\title{
La comunicación organizacional: entre la ley del sistema y la función sintáctica
}

\section{Organizational communication: Between system law and syntactic function}

Recibido: 03/08/2020

Aceptado: 13/11/2020

Publicado: 30/11/2020
Rafael Ávila González ravila@cua.uam.mx https://orcid.org/0000-0002-0284-2645 Universidad Autónoma Metropolitana - Cuajimalpa (México)

José Alfredo Andrade García jandrade@cua.uam.mx https://orcid.org/0000-0002-1139-0214 Universidad Autónoma Metropolitana - Cuajimalpa (México)

Resumen: La antigua reducción de la comunicación organizacional (al dominio de la acción administrativa) está cobrando a los practicantes de hoy las cuentas correspondientes a su indeterminación teórica. Si las abstracciones acerca de sus fines y medios (con las que se construyó en calidad de instrumento) eran una fuerte limitante para su desarrollo estricto, la actual metamorfosis de la economía y la política globales ponen seriamente en riesgo las posibilidades de su reproducción epistemológica y profesional. Los desafíos del mundo de hoy han estrechado el margen de decisión de los términos convencionales de afiliación analítica y funcional. Una nueva revisión teórica a sus supuestos no declarados de autodefinición parece relevante, a fin de otorgarle una mayor consistencia y validez epistémica. El presente artículo espera ser una contribución en ese sentido. 
Palabras clave: Organización, Sistema, Red, Comunicación organizacional.

Abstract: The old reduction of organizational communication to the domain of administrative action is charging today's practitioners the accounts corresponding to its theoretical indeterminacy. If the abstractions about its ends and means, with which it was constructed as an instrument, were in themselves a strong limitation for its strict development, the current metamorphosis of global economics and politics seriously jeopardizes the possibilities of its reproduction. epistemological and professional. The challenges to the world today have narrowed the margin of decision in the conventional terms of analytical and functional affiliation, a new theoretical revision and its undeclared assumptions of self-definition seem relevant in order to give it greater consistency and epistemic validity. This paper hopes to be a contribution in that sense.

Key words: Organization, System, Net, Organizational communication.

\section{Límites del problema}

Valga como epígrafe esta idea de Hegel (2013): "El principio es un contenido determinado de un cierto modo [énfasis añadido]" (p. 87). Subrayar lo anterior obedece a que la determinación formal y el contenido determinado se requieren mutuamente para que este llegue a ser un "asís", bajo las reglas determinadas del sistema reflexivo hegeliano.

Al inicio de la Ciencia de la lógica (la llamada "gran lógica", para distinguirla de la que aparece en la Enciclopedia de las ciencias filosóficas), Hegel (2013) hace un planteamiento demoledor respecto al idealismo especulativo alemán: el ser, sin determinaciones, es lo mismo que la nada, ni más ni menos que la nada (p. 105). Con ese planteamiento rechazó la concepción del pensamiento (dianoia) como pura contemplación del mundo y le asignó la tarea filosófica, anticipada por la intención kantiana de crear un sistema lógico trascendental, de no limitarse a contemplar la realidad, sino de intentar comprenderla.

Esto significa que si queremos sobrepasar esa indeterminación radical del "no-ser-algo", y encaminarnos así a la posibilidad de que ese algo "sea" realmente (to tini), estamos ante la obligación epistemológica de discriminar, de 
poner límites, esto es, determinar por atribución de diferencias. Así es como procedió Aristóteles (2015, p. 190) al optar por la definición de los géneros (génos) de acuerdo con su diversidad: "se dice que son diversas aquellas cosas cuya especie o materia o definición de la entidad es más de una. Y, en general, 'diverso' se dice por oposición a lo 'mismo"'.

La entidad (ousía) es cualificada o determinada según sus especies, materia y definición. La pregunta relevante para ambos personajes (y que es al mismo tiempo la pregunta fundamental en este artículo) tiene que ver con la siguiente interrogante: ¿qué es ese "algo" cuyas determinaciones le otorgan existencia distinguible en cuanto entidad? En términos mucho más disciplinares, ¿de qué orden es la fuente que especifica la "emergencia" de cualquier "algo" organizacional por medios filosóficos?

Si determinar (diáthesis) es poner límites, "de-limitar" cualquier región del mundo (por ahora evitemos hablar de "objetos") es una operación que (de hecho y no metafóricamente) trae esa "región", ese algo, a la realidad, lo que equivale a "traerla a existir" (poión). La operación de discernimiento (en que consiste la disterminatio) no solamente señala los límites y los confines de la materia informe (actuando como separación y división) sino que, al apartar una cosa, un "algo" (res), la pone a resguardo o la somete a escrutinio, aislándola y neutralizando los efectos de su entorno (determinatio). Este momento de la abstracción no puede sino ser experimental (en condiciones de laboratorio) o bien de procedimiento intelectivo. Para el caso que nos ocupa, efectuamos esta segunda opción.

En resumen, trataremos de explicar, es decir, de analizar (discernitur) un problema que a nuestro parecer ha complicado históricamente la claridad discursiva en la teoría de las organizaciones, lo mismo que (por derivación epistémica) de la comunicación organizacional: el problema de la diferencia entre "sistema" y "organización".

De esta forma, nos remontaremos a la Grecia clásica, de donde provienen la mayoría de las voces relacionadas con estos y cuyo uso indiscriminado

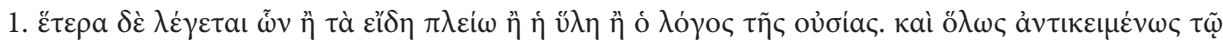

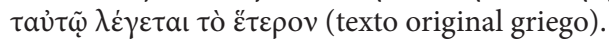


ha ocasionado muchos malentendidos teóricos. En cuanto a la comunicación organizacional, en todo momento la tendremos en cuenta como función organizadora de orden poiético, además de enlace tecno-simbólico. Vale precisar que esta idea parte de los abordajes sociotécnicos de la ciencia, pues consideramos que impulsan una óptica de flujos pragmatológicos que trasciende el plano discursivo y ayuda a situar la praxis del comunicador de las organizaciones. Por el vigor de la nomenclatura vinculada a la comunicación-red de los últimos tiempos (Vidal, 2007; Ponzio, 2011; Barité, 2015), nos parece sugerente atender el entrelazamiento de las categorías de trabajo (érgon) y la configuración sistémica de sus resultados.

De manera que el problema quedaría planteado, en primera instancia, en los siguientes términos: ¿es adecuado el discernimiento entre sistema y organización para explicar (literalmente, "desenredar") funciones importantes de la comunicación organizacional considerada como red tecnosocial? Y, en segundo lugar, ¿esa diferenciación puede ofrecer elementos significativos para ejercer el juicio lógico formal, además de fenomenológico, acerca del tipo de restricciones ambientales con que opera la comunicación en organizaciones formales? En lo que sigue intentaremos obtener algunas respuestas mínimamente válidas.

\section{Organización y sistema-red}

La distinción formulada arriba es importante en la medida en que una lectura analítica la traduce inadecuadamente como oposición ontológica. Ni el sistema ni la organización pueden ser, de ninguna manera, considerados como "objetos" empíricos ni, en consecuencia, como entidades plenas (pléon). En todo caso, ambos constructos, el sistema y la organización, se corresponden con el universal hegeliano: "debido a que son conocidos al mismo tiempo como diferentes, pero no existentes por sí mismos, su unidad no es abstracta, muerta, inmóvil, sino concreta ... Por lo tanto, pese a sus diferencias, quedan siendo en sí mismas [énfasis añadido] el concepto total [del ente], que es colocado en la división solo bajo sus propias determinaciones [diátasso]" (Hegel, 2013, pp. 78-79).

El concepto de uno y otra no es pura indeterminación, sino (para decirlo en términos kantianos) determinación sintética a priori. El "objeto" (supuesto de 
la epistemología clásica) es el ob-jectum, la "cosa" que tenemos a la mano y que podemos inclusive arrojar lejos de nosotros. En su externalidad a la conciencia, pudo reducirse a un guijarro susceptible de captar por percepción sensible. Fueron la fenomenología y la pragmática las que se inconformaron con este dispositivo de escisión entre el mundo intersubjetivo de la cultura (o "del espíritu") y el mundo objetivo de la naturaleza o del cuerpo (esa "máquina de carne", como la llamó Descartes en la segunda meditación metafísica). El dualismo cartesiano fue invalidado, junto con su delimitación radical de sujeto-objeto, en la medida de que no puede proporcionar certeza de absolutamente nada, incluyendo al propio cogito.

Por citar nuevamente la Ciencia de la lógica: "Algo y otro son en primer lugar [énfasis añadido] entes determinados o 'algos'. En segundo lugar, cada uno de ellos es también otro. Es indiferente cuál de los dos se llame primeramente y puramente por eso, algo (en latín, aliud) ... Ambos son, de la misma manera, "otros"” (Hegel, 2013, p. 149). Lo que comparten uno y otra es ser un algo que llega a ser (genésthai) con indiferencia del alter alterum, análoga del "algo otro".

Retomemos aquí la idea, recentrándola. "Sistema” y "organización” se realizan conceptualmente ( $\sin$ carácter de entelequia) pues no pueden por sí mismos "llegar a ser" porque eso significaría reconocer en estos una fuerza creadora que corresponde únicamente a la acción humana, a la facultad productiva o "poiética" (poiesis). La distinción entre estos, su diáthesis, ha sido resultado de largos periodos de fijación semántica y del uso de sus etimos (o raíces de los vocablos consideradas ciertas) en numerosas familias lingüísticas.

Tomemos, sucesivamente, una línea (gramma), la figura de una molécula de carbono (skema), el modelo universal de Galileo (kósmos), un sistema de isohipsas (synhistemi), el mecanismo de un onagro (méchane) y un diagrama neuronal (morphé). Todos estos son hechos y figuras (prágma) organizados, si bien con grados distintos de complejidad. Pero, ¿en qué consiste, precisamente, esa cualidad de "organizado (systéso)"? ¿Qué queremos indicar cuando decimos que "algo" tiene esa propiedad? Sugiere Aristóteles (2015) que, "en cuanto al orden" algunas cosas se disponen (dispono) relativamente "por estar colocadas conforme a alguna regla, en relación con algo único y determinado" (p. 193). 
Es lo que nos parece el elemento central, la característica sine qua non de organización y sistema: el orden (táxis). Fuera de este (aunque se trate de órdenes diversos y superpuestos, coexistentes como en Bergson) queda lo indeterminado y de-forme, lo monstruoso o divino, mas no lo humano.

La mecánica cuántica y la teoría de la complejidad, por poner un par de ejemplos, han reconocido que el universo sólo puede ser descrito con precisión aceptable (no definitiva) si se conocen detalladamente y en profundidad las condiciones iniciales de un fenómeno y se contemplan adecuadamente en el momento de la observación (en términos técnicos, una "medición"). Aun si hoy, pongamos por caso, no podemos predecir la formación de un huracán (o explicar cómo es que se produce el entrelazamiento de partículas subatómicas, o pensar la gravedad no como "fuerza" de la teoría estándar, sino como resultado de la torsión del espacio tiempo) aun si todo eso es cierto, sabemos que los modelos e interpretaciones teóricas del mundo físico-químico tienen una razonable posibilidad de ampliar paulatinamente (aunque de manera no lineal o progresiva) la comprensión de esos "algos".

A la suspicacia de un ingenuo determinismo mecánico responderíamos que este es un planteamiento menos metafísico que la actuación de fuerzas misteriosas actuando sobre el universo o, incluso, sobre el inconsciente y las pasiones humanas. Para decirlo con absoluta claridad, no compartimos las interpretaciones progresivas de la historia (tanto de Kant como del propio Hegel) por considerarlas moralmente cuestionables en su idealización, pero rechazamos (por socialmente inviable) la negativa a pensar y poner atención sobre lo que ocurre en y entre nosotros-mundo. De no hacerlo, incurriríamos en la imposibilidad de formular cualquier cuestión ética futura, único camino para ejercer legítimamente la facultad crítica del juicio moral (krisis y de ahí kritiké).

La idea de orden (como manifestación aristotélica de apego a una cierta regla) ha sido expuesta no solo en la Metafísica, sino también (entre otros trabajos suyos) en Acerca del cielo: "Dado que la totalidad [ti pánta, to hólon], el todo y lo perfecto no se diferencian en cuanto a la forma [ten idean, eidos, que aquí denota la 'esencia' de algo], sino, en todo caso, en la materia [hýle] y en aquello sobre lo que se dice, sólo el cuerpo [soma, phýsei], entre las magnitudes (metros), es perfecto: sólo él, en efecto, se define por el tres [principio, medio y fin], y eso es un todo [to pan, to hólou, el Universo]" (Aristóteles, 1996, p. 43). 
Esa concepción armoniosa y "perfecta" del universo es la fuente más antigua en Occidente del concepto de "orden" (syntáxis). La disposición (dispono) y movimientos regulares de los astros y las "estrellas errantes" (los planetas), con la Tierra en el centro del Todo, llevó a Pitágoras a hablar de la música de las esferas (los círculos estelares donde estaban fijas las estrellas, el sol y los planetas), al tiempo que intuía en el número la clave ordenadora (y hasta equivalente) de esa disposición, del mismo modo que la armonía es de la música (idea que lo condujo al canon de una sola cuerda). ${ }^{2}$

Esta representación del universo como perfección tuvo varios referentes adicionales. Probablemente sea Parménides el ejemplo más conspicuo de todos ellos. Al describir al ente ("lo que es", to eón, participio del verbo "ser", to einai) como una esfera, dio a luz una representación del cosmos que continúa hasta nuestros días en diversos ámbitos, tanto en la física, como en las ciencias sociales y las humanidades. Si el ente es esférico, su centro es equidistante hacia cualquiera de sus extremos: en eso radica su perfección. "El ente se reúne con el ente", escribió en su célebre poema, "es completo en toda dirección, semejante a la masa de una esfera bien redonda, equidistante del centro en todas direcciones" (Lisi, 2015, p. 293). Esférico y sin límites, completo, absoluto; o sea, sin término exterior, así se constituye la representación occidental del universo, la "totalidad".

Lisi (2015) da a conocer que poco antes de Parménides, en la época de Heráclito, la palabra para designar al orden era kósmos: "[Kirk] cuestiona que en la época de Heráclito kósmos significara algo más que 'orden'. De todos modos, admite que no es un orden vacío, sino un 'orden de cosas"'. Kerschesteiner, por su parte, "rechaza también un concepto abstracto de orden en favor de un concepto concreto de universo. Por ello, nosotros entendemos que, en Heráclito, kósmos significa 'mundo', como 'orden de todas las cosas"' (citado en Lisi, 2015, p. 212).

La nota nos pone en una tesitura del orden como disposición (syntithemai, dispositio) relativa entre los elementos de la totalidad. Eso explica que, en

2. En la Grecia antigua, la harmonía designaba a la música, mientras que este término se refería al conjunto de las artes otorgadas y guiadas por las Musas, mismas que con el paso del tiempo se llamarían "Bellas Artes". 
la transculturación grecolatina, Plinio el Viejo asumiera ese significado, añadiendo además otras precisiones:

El mundo y todo aquello que con otra denominación se convino en llamar cielo, en cuyo seno transcurren todas las cosas ... es sagrado, eterno, inconmensurable, un todo en el todo o, mejor dicho, él mismo el todo: infinito y similar a lo finito, concreto en todas sus partes y similar a lo inconcreto, compuesto esencialmente por la totalidad de elementos intrínsecos y extrínsecos; no sólo es la propia obra de la naturaleza física, sino también la misma naturaleza física. (Plinio, 1995, p. 337)

Además de esas propiedades, al igual que hiciera Marco Varrón antes que él, recuerda la sinonimia de kósmos y mundus con la belleza: "yo desde luego me dejo guiar también por el consenso de los pueblos, pues los griegos lo designaron con la palabra de la belleza, como también nosotros lo llamamos mundo por su perfecta y absoluta hermosura" (Plinio, 1995, p. 337).

Esa perfección y belleza del mundo será una constante hasta la Escolástica, e incluso llegará hasta Galileo y Newton, convirtiéndose en paradigma del orden deseable y no solo natural. Aristóteles (1996, pp. 41-48) lo determinará como el espacio y el movimiento constante y cerrado sobre sí mismo, sin puntos de partida y de llegada, pero explicables por la instancia originaria del llamado "primer motor", inmóvil, no generado y por eso eterno, existente en sí y por sí mismo (auto kath auto). En la Escolástica y en los siglos XVI al XVIII será motivo de ejemplaridad (paradigmae) para venerar "la perfección" del cuerpo humano y la composición física entre los seguidores del médico Galeno y el arquitecto Vitruvio, destacadamente el anatomista Vesalio y el teólogo Manuel Serrano, quien junto con Ottavio Scarlatini, se refirieron a la composición y articulación del cuerpo como "fábrica corporal".

¿Qué podemos decir después de este recorrido? Que el orden es una cierta disposición relativa de los elementos de un todo en función de una regla o canon determinado. Así, el orden no es una realidad objetiva, sino que se refiere a una expectativa, sea esta de regularidad espacio-temporal o de composición de ideas. Corresponde (digámoslo siguiendo a Bergson) a una expectativa culturalmente ponderada. 
Para expresar tal orden hemos puesto atención a algunos términos elementales, en particular cuatro de estos: táxis, sýntaxis, synisthemi y syntithemi. Sus significados son múltiples y muchas veces aparecen entremezclados con otros semejantes, por lo que es preciso puntualizar un par de cosas acerca de ellos para evitar confusiones mayores.

Táxis es un concepto más bien general, ese contra el que se manifestaron Kirk y Kerschesteiner, y corresponde al ordo latino (orden "usual" y regular, como la sucesión numérica u ordinalis); a lo sumo, se vincularía además con ordinatim, en tanto propiedad de un "orden" dado, pero que no deja de ser mayormente abstracto por su alto grado de generalidad. Los otros tres, en cambio, son más específicos y, en realidad, los últimos dos se distinguen principalmente como variantes lexicales griegas. Euclides (2013), por ejemplo, empleaba ambos para expresar concurrencia geométrica, pero con el uso específico del isthemi para la línea vertical de sus elementos, en tanto que para la línea horizontal empleaba la voz títhemi. "Utiliza fundamentalmente dos verbos para trazar una línea: ístemi 'poner derecho' y keimai 'estar tendido', también usado como 'perfecto pasivo' de títhemi, 'colocar'” (Euclides, 2013, p. 136).

El cuarto elemento (syntáxis) viene sucedido por el latín compono, que resalta su atributo de compuesto "bien organizado", es decir, con estrictas relaciones en la disposición de sus partes (méros). En su uso literal, tiene que ver con la composición de las sílabas (syllabé) a partir de las letras. Estos (en un todo compuesto y, en los términos indicados, "organizado") serán llamados, por extensión, "elementos" (ta stoixeia), lo que por el principio de inmediatez hace de esa totalidad un compuesto divisible y ya no indivisible como propuso Parménides.

De ese modo, syntáxis se vincula estrechamente con sýnthesis, no solamente por el prefijo "con" (syn), sino especialmente porque thesis se refiere a la "posición", espacio-temporal o de juicio, de una entidad. La syntáxis le añade el carácter relativo y de complejidad, entendiendo por este último término, en principio, nada más que "compuesto" (sýstasis), en calidad de contrario de simple (aploeidés).

Pero esa sýstasis o compuesto designan (de acuerdo con Aristóteles) un "sistema físico", debido a que la acción de unir o conjuntar implica también el 
acto de fijar o de erigir. Tenemos entonces un triple movimiento: conjuntar (sýstasis), organizar (diakosmos) y estabilizar (sýnisthemi). Esta última es lo que llegará hasta nuestros días con el nombre de sistema: sýntíthemi, significando originalmente (por su raíz -stare) la acción y efecto de instaurar, erigir, sostener e instituir, con muchos otros términos conexos.

A esta entidad creada por medio de la conjunción de "cosas" que son sus elementos, le son aplicables "operaciones de disposición" relativa de los mismos, con el efecto de estabilizarla en cuanto "id-entidad" singularizada (uno, hén). Así pues, el constructo sistema "llega a ser" (uparxé) debido a la acción organizadora. Hay un "afuera" del sistema que es el operador, (el demiourgo, el técton) "efectante" del constructo por medio de su actividad poiética. Tengamos presente que la "organización" (como sustantivo o en cuanto entidad) está inscrita desde siempre en la relación de medios y fines.

Sabemos que el compilador de los trabajos aristotélicos puso el nombre de $\mathrm{Or}$ ganon a los que le parecieron propios de la lógica, dándole así un cariz instrumental. La lógica, instrumento del pensamiento (dianoético), lo que sugirió a Francis Bacon titular su exhorto por las ciencias inductivas como Novum Organum. Al respecto, el principal texto griego que (como tal nos ha llegado, aparte del aristotélico) es el discurso Sobre la organización de Demóstenes, en el cual el considerado más grande orador griego hace un alegato para apoyar al ejército y hacer un uso racional de las contribuciones fiscales (que, curiosamente, también se llamaban syntáxeis) para el bien de la pólis y los demos:

Sostengo la necesidad de que estéis organizados (syntetáxthai) y que la organización (sýntaxin) sea la misma para recibir dinero público y para hacer lo que conviene. Ya antes traté ante vosotros de eso y expuse el modo en que podríais organizaros (syntaxtheíete), los hoplitas, los caballeros y cuantos estáis fuera de estos órdenes, y la forma en que cierta abundancia de medios podría llegar a ser común para todos. (Demóstenes, 1980, p. 288)

El sistema se constituye gracias a la capacidad poiética de la actividad organizadora, que a su vez efectúa una doble operación, de composición y separación (sýnthesis y diaiéresis) de la entidad compuesta, ahora llamada sýnolon. Pero el sistema (por sí solo) no puede ser entidad compuesta de materia y forma (syneilemménos), sino únicamente materia (es decir, hipokeimenon) 
sobre la que actúa la forma, el eidos, la organización: el lógos. Esta forma no es corruptible ni se genera, dado que es una capacidad (dýnamis) o función (energeía) propia del ser humano, siendo la Forma "en sentido pleno", pues "no se genera aquello en que consiste ser-casa, sino aquello en que consiste ser-esta-casa-particular. Más bien, las formas existen o no existen, sin generación y corrupción" (Aristóteles, 2015, p. 271).

Desde esta perspectiva, el principio activo del sistema es la organización, mientras que su articulador sería la conexión de los elementos, el tejido, la red ( $d i$ ktuon) que los conecta (synepláken, committo). En el ejemplo más utilizado al respecto (la sinapsis de la red neuronal) Varrón nos echa una mano para comprender este concepto, tan de moda hoy en día: "El peine (pecten) tiene su denominación porque mediante él se desenreda (explicatur) el cabello ... Lo que podía retener el cabello, a partir de rete 'red' recibió la denominación de reticulum (rete procede de raritudo, 'cualidad de no ser compacto')" (Varrón, 1998 , p. 241). Sin duda, esta denominación trae a la mente la distinción que hace Weick entre sistemas estrictos y sistemas flojamente acoplados. Según lo dicho, y siendo consistentes con la teoría de la complejidad (citado en Wagensberg, 2001) entre la rigidez y la laxitud sólo existe una diferencia de grado.

Por su parte, el principio articulador de la organización no es el enlace o entrelazamiento distintivo de cualquier red (y de cualquier sistema). Su principio de acción son las funciones, mismas que traen a colación las causas aristotélicas:

Todas las cosas que son compuestas tienen materia y forma, y se descomponen en estas ... [Pero otras cosas], cuyos enunciados son solamente de la forma, o bien no se descomponen en absoluto o bien no se descomponen del mismo modo ... Por consiguiente, las partes que lo son en cuanto materia, son posteriores; por el contrario, las partes del enunciado, es decir, de la entidad según el enunciado son anteriores todas o algunas de ellas". (Aristóteles, 2015, pp. 256-257)

La causa material (hýle) es requisito de existencia de la entidad compuesta, pero es la causa formal, la Forma (la idea, el eidos), la que determina en última instancia al ser de la entidad, inclusive por sobre la causa final (télos). Esa forma (no confundible con la "figura" o skema) es pro-curada por el organizador (systátes), quien se formula un orden de acuerdo con los fines y la 
naturaleza de la entidad (táxin kai kósmos kai phýsin). Ese organizador tiene en sus manos, o representa, la causa eficiente (érgon), la acción externa al sistema que le otorga existencia y estabilidad con sus operaciones recurrentes.

De modo que la noción de sistema está vinculada con la de interconexión física y simbólica, mientras que la organización mantiene una ambigüedad más notoria. De un lado, se reconoce como operación generadora y reguladora del sistema, pero simultáneamente se intenta otorgarle calidad de ente, razón por la cual sistema y organización suelen confundirse tanto y tan a menudo: "la idea de sistema social sigue siendo trivial: la sociología que usa y abusa del término de sistema [desde Pareto hasta Parsons], no lo elucida jamás: explica la sociedad como sistema sin saber explicar qué es un sistema” (Morin, 1986, p. 122).

Aparecen, en seguida, un par de consecuencias relacionadas con esta indeterminación teórica. O bien se asume una idea de que el sistema se auto-organiza (es decir, se integra y diferencia) tomando como base de reproducción temporal subsistemas cada vez más ínfimos y disfuncionales, en la línea de la complejidad creciente de Luhmann (2009) o la organización (el prágma, el "hecho" de organizar) se reifica innecesariamente al pasar de ese algo hegeliano (to tini) que es al mismo tiempo un "otro" para el sistema, a un "esto", un "qué es" (to tí esti, res) confundido (asystatéo) con aquél debido a que no suelen exponerse con claridad las determinaciones ("predicaciones") que se le efectúan al concepto.

El resultado constante es el colapso de ambos, sistema y organización. No por simple improbabilidad física, sino por asystaxía: por las imprecisiones teóricas que impiden ver que (en medio de estas, entre ambas) siempre ha existido una red, ya de energía, ya de operaciones, inclusive de símbolos, que hacen posible su existencia empírica conjunta, pero no su unidad simbiótica pues, como hemos dicho, se trata de órdenes categoriales diferentes.

\section{Del sistema-red a los flujos (des)organizados: tiempo y coyuntura his- tórica}

En la perspectiva de los sistemas auto-organizados se sobreponen varias clases de enunciados. Eso es inevitable cuando el análisis se lleva a cabo en distintas regiones de la realidad, pero con un interés único, de ahí que sea 
necesario determinar lo que uno hace si no quiere perderse en las tinieblas de los discursos autoevidentes o, peor aún, en la esfera fantasmática de una ciencia libre de conceptos.

¿Quiénes son los systates (o poietes) que ostentan la capacidad de organizar el sistema al decidir las conexiones entre los elementos? Los filósofos clásicos los llamaron krátos o hegemones, y al poseedor de derechos ciudadanos en las poleis, politeían (Demóstenes, 1980, p. 94). Lo que conocemos como La República, de Platón (2015a), en realidad se llamó Politeía, es decir, "sobre la gestión de la pólis"; sin embargo, Cicerón lo tradujo a la forma republicana de gobierno y lo llamó ResPublica.

En ese mismo texto indicó las clases de "oro", "plata", "hierro" y "bronce" (asignados estos últimos a los agricultores y artesanos), además de los cuatro sectores políticos: gobernante o "guardián”, "legisladores" y "militares". Los "sacerdotes" debían provenir de las dos primeras, hombres (sic) que hubieran pasado a retiro. Dichas características, junto con las virtudes cardinales (phrónesis o "prudencia", andreia o "valentía", sophrosyne o "templanza" y dikaiosyne o "justicia") configuran el Estado griego de la época, con sus cortes y continuidades, sin pasar por alto la importancia histórica de la Asamblea de ciudadanos (politeían) que se reunía en el ágora para decidir asuntos públicos por medio de la deliberación.

Aristóteles señala en La Política que el hombre es un "animal social" porque dispone de palabra (lógos). Hay que tomar en cuenta que politikón zóon refiere precisamente a su calidad de habitante de la comunidad política, la sociedad, la pólis, sin la cual no pueden comprenderse ni el demos ni el oikos, ni el pueblo ni el hogar familiar. Por esos mismos años, Jenofonte escribió la Oikonomía, que aborda la buena "gestión doméstica", equivalente a la politeía en cuanto a su objetivo, pero distinta por la cantidad de mandos y asuntos a considerar. El esposo ejerce la autoridad en la familia, pero la comparte con otros ciudadanos en la cosa pública (politiké). En Timeo, relata así la creación del orden universal y humano:

Digamos por qué causa el hacedor [demiourgo, literalmente "ar-

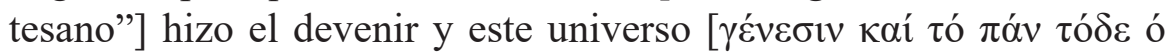

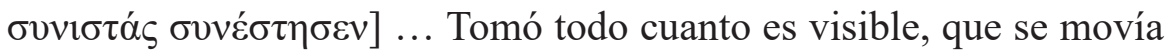
sin reposo de manera caótica y desordenada, y lo condujo del des- 


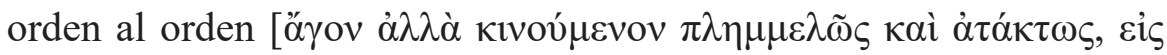

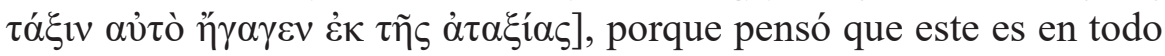
sentido mejor que aquél ... Es así que según el discurso probable debemos afirmar que este universo llegó a ser un viviente provisto de alma y razón por la providencia divina. (Platón, 2015b, p. 167)

En La República complementa esta concepción del universo como una totalidad organizada según el principio de la perfecta imagen divina, asumida en la "doctrina de las ideas" y que revela claramente la distinción entre el sistema y la organización: "Y así, al florecer el Estado en su conjunto y en armoniosa organización, cada una de las clases podrá participar de la felicidad que la naturaleza les ha asignado" (Platón, 2015a, p. 205). La sociedad queda también regulada por la razón divina y, durante muchos siglos, esa concepción servirá de motivo para sostener posiciones únicas y rechazar la crítica. No en balde Spinoza y Kant señalaron como principio de la Ilustración el respeto y ejercicio de la facultad individual de pensamiento (sapere aude).

Como hemos especificado, las palabras synisthemi y syntithemi comparten una misma raíz, histemi, que en sí misma significa "sistema", pero en el sentido que ya señalamos: erigir, poner verticalmente, sostener, fijar, "instituir". Y esto es hermosamente esclarecedor. Pasó al latín como stare, y de ahí los vocablos de, entre otros, "instaurar", "instancia", "Estado", "estatua", "institución". Pero en ese transcurso quedó en el olvido su valor cotidiano de poner en pie y apuntalar. El sistema, en su origen, es la institución organizada y fija, erigida como respuesta a coyunturas históricas pero que suele mantenerse durante mucho tiempo, casi siempre más del que le correspondía o se suponía en un inicio.

Bien, pongamos que esta larga trayectoria pudiera servir para desenredar la indistinción entre los conceptos de organización y sistema. ¿Cómo se traduce todo lo anterior al examen de la comunicación en cuanto al prágma organizacional? Primero, interesa porque los hegemones de las organizaciones (deberíamos decir "sistemas", pero estamos empleando aquí el término usual de la teoría de la organización) son los directores, quienes ordenan y conducen, los tenedores de la recta opinión (ortho doxa) que pasaron al latín como los practicantes del verbo regere (dirigir); y como parte de su núcleo de operación (esto es, de la función “organización”, los funcionarios), con los que teóricamente se acuerpan, la cadena de mando del aparato administrativo, toda 
la cual actúa según la lógica el verbo gerere (gestionar, hacer por mandato de otro y por medio de otros, como en la teoría de la agencia). El agere (correspondiente a la poiesis y al poiein) al hacer y producir queda reservado a lo que históricamente fueron los siervos y los artesanos (tekton) y que perdura con la distinción científica de artes liberales (ciencias fundamentadas en la episteme) y artes técnicas (téxnoi) o artes manuales (érgasía).

En segundo lugar, muestra que el análisis de las formas organizacionales debería extenderse también al largo plazo, como sugirió Braudel (1974, p. 94) con las temporalidades larga, corta y acontecimiento, semejantes a su vez a los tres tipos griegos del tiempo: aión, krónos y kairós. Los cortes en el capitalismo o la modernidad no son suficientes, dado que esas denominaciones suelen ser problemáticas para describir procesos históricos de largo aliento. De todos modos, investigaciones como las de Mumford $(2013,2016)$ pueden ser útiles para considerar ampliar el rango de atención.

En tercer término (y radicalizando la interpretación) mientras que los comunicadores organizacionales asuman como propia una otra perspectiva (entre las muchas que circulan en el mundo académico) habrá un grado distinto de ordinación respecto a las directrices gerenciales. Sin ser esto un error en sí mismo, sí implica (im-pleko, plectos) restricciones fácticas a la acción epistemológica o de profesión.

La primera distinción debida en el aspecto semántico, entre isthemi y tithemi (articuladas por la noción de théma, "poner" o "colocar"), viene acompañada por otra con mayores implicaciones técnicas: el par indicado es claramente distinto de la sýntaxis. La primera distinción conduce a las nociones de sistema e institución, al poner y fijar (synisthemi); la segunda, a la disposición de lo diverso (diáthemi), a conjuntar, a la organización como un "algo" empírico, permitiendo incorporar los lugares de producción, la antigua fabrica, la opifficina de los artesanos (los opifex), el érgon y la energeía, la poiética del cuerpo humano.

De este modo, a la organización podríamos concebirla técnicamente, con las precauciones del caso, como un campo no escalar ni conservativo, sino vectorial complejo, en donde la estructura del sistema viene dada por la comunicación, equivalente a las operaciones organizadoras. Esto supone asumir a la comunicación como generador de la organización del sistema (genesthai) y al 
mismo tiempo como su delimitador (determinátor), lo que previene el riesgo de atribuir identidad (instituida) a "organización" y "sistema", gracias a privilegiar el análisis de sus distintas fases o estados en completo dinamismo (o sea: enexon versus exón, "proceso-de-siendo" versus "estado-de-ser").

Por no haber insistido en el asunto del trabajo como su locus fundamental (y haberlo exiliado casi por entero hacia la provincia sociología apellidada así) la teoría de la organización terminó sucumbiendo al encanto de la cosificación sistémica. Cuando llegaron los años después del festival que significó el boom de la posguerra (y la tasa de ganancia se deslizó pendiente abajo principalmente en la economía más importante del mundo) el remedio que se procuró (el pharmakon, con su connotación opioide) fue la mundialización de la crisis, la reorganización mundial de la economía en beneficio del capital financiero internacional y en perjuicio de enormes masas de subempleados, reminiscencia remota de un lumpen-proletariado que ya no puede ser siquiera eso (Brenner, 2013).

Si las llamadas "organizaciones formales”, así como las economías y los regímenes políticos concretos, fueron siempre (así sea parcialmente) sistemas instituidos que al interconectarse daban identidad a las distintas culturas y épocas históricas en un desarrollo desigual y combinado, las tecnologías de información y comunicación se convirtieron en los últimos treinta años en el nuevo agente favorito de los hegemones globales.

La teoría de la agencia y la nueva economía de la empresa se enfrentaron con el nuevo institucionalismo y el regulacionismo francés, buscando la consolidación de un nuevo juego de llaves para las viejas reglas del juego: la socialización de costos y la privatización de beneficios. El problema en ese intento, es que no se construyeron nuevas instituciones reguladoras de los nuevos sistemas: el mercado de capitales y la glocalización productiva fueron dirigidos como misiles en contra de los salarios y la vida digna de la población globalizada involuntariamente, lo que puso en el tapete de las discusiones el verdadero potencial emancipador de las tecnologías comunicativas.

Enfocado en la reciprocidad técnica de las redes sociales, Barité (2015) las define como "estructuras de comunicación horizontal, libre y abierta, que permiten la interacción remota entre personas ... Se basan en la reciprocidad, 
a partir de la idea de un intercambio paritario a partir de iguales rangos de derechos y posibilidades" (p. 129). En contraste con una vida cotidiana profundamente alterada, los gestores de la madeja comunicativa desenredan sus hilos con intereses todavía tradicionales y motivaciones monetarias.

La administración global del trabajo, es decir, los gobernantes del saber científico y político nacional y mundial (diokekós ten pólin kai ten kósmos), inclinaron para un solo lado la cancha y afectaron enormemente el modo de vida de quienes (asalariados de piso) fueron expulsados del mercado de trabajo industrial como consecuencia de la llamada "economía del conocimiento". Si la composición técnica del capital en el sistema industrial tenía como productor de valor al trabajo (capital variable), en la nueva economía ("la economía en red") es el capital fijo (equipos, inversiones, instalaciones) el que reclama ese mérito.

Eso tiene que ver con al menos dos fenómenos concurrentes. En la última década del siglo XX creció desproporcionadamente el flujo de capitales entre naciones soberanas. La magnitud del comercio de inversiones triplicó al comercio de bienes de capital y de consumo. Entre las causas estaba lo que Elmar Altvater denominó “capitalismo de amiguetes", círculos político-financieros que se apropiaron de los bienes nacionales con legislaciones a modo y sistemas de justicia coaligados, así como la compra-venta de los presupuestos públicos mediante la oferta de bonos nacionales a plazos ridículos y con tasas de interés muy presionadas por la voracidad de los bancos de inversión y las calificadoras de riesgo apalancadas por el Departamento del Tesoro norteamericano (Panitch \& Grindin, 2015).

Ese modo de operación (que llamaremos "emergente") en realidad acentuó la tendencia de las regulaciones al modelo de acumulación, con desequilibrios constatables empíricamente. Por ejemplo, la revista The Economist, baluarte del liberalismo económico y tributario, tuvo que admitir que se ha profundizado la desigualdad en los países centrales, tanto en el ingreso dinerario por hogar, como en la concentración económica y nuevos modos de expoliación laboral (contratos cortoplacistas y retiro de políticas de seguridad social). "No todas las teorías del señor Piketty son aceptadas entre los economistas, pero se asume ampliamente que los trabajadores están recibiendo una menor porción de la riqueza mundial, en tanto que se ha incrementado la de los inversionistas" (The Economist, 2019, p. 11). 
Entre las implicaciones organizacionales de esta situación se podría contar que el capitalismo de gerentes ha llegado a su fin y que la tendencia hacia un nuevo modo de regulación debería someterse a discusión más allá de las paredes parlamentarias y legislativas, en las plazas públicas donde (hasta hace no mucho tiempo) se deliberaba sobre los asuntos de la república. Esta interpretación supone que la gestión global del capitalismo de libre mercado y de convenios comerciales regionales o bilaterales se está rezagando, o más bien, quedando desfasado con respecto a las trayectorias económico-financieras y laborales. El Consenso de Washington fue incapaz de producir mecanismos estables y duraderos que sustituyeran al Banco Mundial y al Fondo Monetario Internacional, emanados de los Acuerdos de Breton Woods en la posguerra. La Organización Mundial de Comercio ha mostrado escasa autoridad para hacer observar sus reglas por los países más poderosos y lo mismo sucede con los pactos ambientalistas cristalizados en el Acuerdo de París.

No es muy difícil afirmar que en estas circunstancias el capitalismo global se encuentra desafiado desde su entraña, de otra manera no podría explicarse, desde el conventualismo teórico, el triunfo de un personaje como Donald Trump, con un discurso demasiado regresivo frente al de sus antecesores inmediatos. Pero no se trata de un capitalismo desorganizado (por más que se lo califique como asýntakto), sino en transformación sistémico institucional (pleonasmo necesario para exponer la idea): asýnhistemi, valga decir, debilitado y en proceso de recambio de su campo de fuerzas.

Esta es la coyuntura en la que se aspira a reinterpretar la comunicación organizacional: se trata de un mundo convulsionado y sin ligaduras universales, sino de repliegue hacia nuevos refugios nacionalistas y comunitarios que tanto preocupan a personalidades como Jean-Luc Nancy, Roberto Esposito, Giorgio Agamben, entre otros. Angenot (2010) analizaba algunos fenómenos "heterocrónicos" que son muestra de la aceleración de la mudanza o, más bien, la contrariedad perceptual y epistémica de esta coyuntura crítica. Por su valor, lo citamos en extenso:

El objeto año solo es una entidad arbitraria, un corte en un flujo continuo ... Sin embargo, desde un punto de vista menos arbitrario, el año corresponde a una coyuntura, una configuración de tendencias y de emergencias reforzadas por modos de corta duración, el impacto de los acontecimientos de la actualidad cuya sensación se agota rápida- 
mente. Estos diversos aspectos son "heterocrónicos”; por lo demás, no se podría datar la emergencia o el cambio. Incluso las crisis coyunturales solo producen en el discurso social efectos "reveladores" ampliamente anticipados y con persistentes remanencias posteriores. Las coyunturas son configuraciones inestables en las que los doxógrafos se afanan en descubrir "los signos de una época" y por interpretar el presente como cargado de una identidad significativa". (Angenot, 2010, pp. 54-55)

La coyuntura es la unión y cruce de caminos, rutas, temporalidades. La coyuntura misma es el acontecimiento braudeliano y, en tanto que tal, debemos aprender a resistir su fascinación para no quedarnos únicamente "con la espuma del mar". Pero este 2020 está siendo especialmente crítico para las formas colectivas de vida, no sólo para el modo de acumulación. Los economistas aseguran que superará al crack de 1929 y no tenemos duda que así sea. Sin embargo, en este achicamiento del ciclo económico de Kondratiev, que reduce cada vez más la curva de expansión y crisis, la que estamos viviendo se sale de la norma. El virus pandémico llegó como las antiguas Erinias, las "furibundas", y reveló la horrible realidad de la configuración sistémica. Frente al 50\% de autoempleo en espacios públicos, la población de las economías más inequitativas experimenta un retroceso a las condiciones laborales, sociales y de salud del siglo XVIII. "Trabaja o desfallece", se decía anteriormente en los círculos críticos; hoy, la divisa es otra, mucho más hiriente: "Muere de rápido de enfermedad si no quieres morir lentamente de hambre".

Altvater (2011) subrayó la peculiaridad de la crisis financiera del 2008-2009 originada en Estados Unidos. Dado el modo fiduciario del dinero (ya lejos del patrón oro) no deja de sorprender que el país que la produjo (debido a mecanismos perversos de inversión) haya recuperado su crecimiento dejando a la zaga a muchos países que vieron cómo se destruían las cadenas productivas que habían tardado décadas en construir. Apunta directamente al papel desastroso de las calificadoras, pero no sólo a estas, cuando señala que "la liberalización y el desafuero de los mercados crearon un espacio libre que generó instituciones monstruosas, esta situación es intolerable y debería ser modificada" (Altvater, 2011, p. 150).

En la coyuntura de 2020, esa opinión (expresión doxográfica) acentúa su validez. El capital de libre mercado abandonó a su suerte a la llamada "econo- 
mía real", fuente de su acumulación y su poderío ideológico. Es consistente con su lógica interna, presionar mediante la demanda el aumento de la tasa de interés, sin preocuparse de la suerte que corran los pequeños y medianos empresarios, lugar del empleo formal más significativo, con la reducción consecuente de la tasa de ganancia.

Asimismo, se ha redimensionado el papel de los rentistas en la producción de la riqueza. Adam Smith redujo su participación en la renta nacional como parte de su controversia con los fisiócratas (en especial con Quesnay) y reconoció en su modelo solamente dos factores de la producción, capital y trabajo. Según él, ambos producen valor, mientras que los rentistas únicamente aparecen como usufructuarios, sin justificarse como agentes productivos.

Hoy en día, existe un movimiento economista que pretende definir este momento global con la inversión de factores. Las nuevas técnicas de producción permiten abaratar los costos tanto por escala como por diversificación, además de conectar multiplicidad de regiones ("ciudades globales", les llaman Lash y Urry) en tiempo real. Tales características (que son las más evidentes) han llevado a proponer que la importancia de los factores de la producción se ha invertido y que es por medio del capital fijo (equivalente a la disminución de la proporción aportada por el trabajo en la producción de valor) como se realiza la plusvalía, al margen de la cantidad de plustrabajo incorporado en la utilidad del capital.

Es interesante anotar que David Ricardo coincidió con la perspectiva de Smith acerca de la economía como ciencia enfocada en la producción de la riqueza, igual que Jenofonte lo planteó en Oikonomía, o Aristóteles en la Política, o más acá, en el siglo XVII, el mercantilista Montchrestien. Incluso Hegel, que no interpretó la reciprocidad comunitaria como lo hiciera Spinoza (reciprocidad moral) o como Smith (egotismo funcional), sino como una mezcla de ambos: reciprocidad funcional. No obstante, la forma idílica como trata a las corporaciones (organizaciones), hace de su modelo una sociedad corporativa. Las corporaciones median entre la familia y la sociedad civil en la cual se inscriben.

La familia es unidad y la corporación escinde a sus miembros por la vía del trabajo asalariado, pero de esa manera, según el punto de vista de Hegel, "los hace ser algo", otorgándoles dignidad de clase; de otra manera no la tendrían, pues los oficios no pertenecen a una comunidad legítima (como las corpora- 
ciones) y deberían demostrar sus habilidades ininterrumpidamente (texnotes). Es por ello que las corporaciones son las que brindan seguridad a las familias.

Nos parece un tema muy atractivo para revisarlo a la luz de los acontecimientos del presente, sin pasar por alto cómo Hegel anticipó el desplazamiento del trabajo humano por las máquinas en el sistema corporativo. Con ese tema podemos pensar en la sociedad del siglo XX y su transformación sistémica mediante el recurso a la corporación-máquina integrada en la sociedad civil de la modernidad autoconsciente (Hegel, 2004).

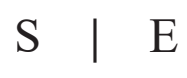

Se traza una línea sobre la pizarra: ese acto determina la creación del sistema: de un lado queda este y del otro el entorno. Así inicia Luhmann (2009) el planteo del sistema como diferencia: "El sistema es la 'diferencia' que resulta de la 'diferencia' entre sistema y entorno ... Por tanto, la teoría de sistemas no comienza su sustentación con una unidad, o con una cosmología que represente a esa unidad, o con la categoría del ser, sino con la diferencia. Siempre ha existido en la tradición de pensamiento una representación de la diferencia. En el pensamiento helénico encontramos el uso extendido del diapherein (diferenciar), pero siempre considerado como un tratamiento teórico marginal" (p. 78).

En este artículo hemos intentado elaborar una posible respuesta a las preguntas siguientes, que se entrelazan con las que presentamos al inicio: ¿qué significa esa "autosustentación”? Más aún, ¿cuál es el sentido, el "interés" de determinar un sistema con un gesto de esta clase? Sabemos que Luhmann (2009) desarrolló un amplio sistema teórico "acerca del sistema teórico" de la teoría de sistemas, por lo que tenemos la impresión de que al final (de cualquier manera, no siempre abiertamente declarada) la teoría autopoiética luhmanniana es tan solo aplicable a su propia configuración. Como un juego de Lego que se compone según el operador vaya optando entre rutas distintas de crecimiento.

Pero el mundo de hoy con sus organizaciones y sus sistemas (al "acoplarse" funcional y operacionalmente) traen consigo costos humanos que son mucho más importantes que los correspondientes a cualquier capital acumulado. No tenemos forma de evadirnos: tenemos la oportunidad de tomar decisiones 
también, mas estas deben incluir a los modos de composición y de disposición relativa entre sectores económicos y grupos sociales de estricta determinación y concreción.

La comunicación organizacional camina hoy al borde del acantilado y no sabemos cuál será su manera de renovarse y según cuáles principios. Pero deben ser algunos (los que sean) pendientes de la comedia humana de este año que se va. No podemos (como participantes de un dominio disciplinar) repetir el truco pitagórico de esconder los números irracionales para no echar a perder la música de las esferas.

\section{Fuentes consultadas}

Altvater, E. (2011). Los límites del capitalismo. Mar dulce.

Angenot, M. (2010). El discurso social. Siglo XXI.

Aristóteles. (1996). Acerca del cielo. Gredos.

Aristóteles. (2015). Metafísica. Gredos.

Barité, M. (2015). Diccionario de organización del conocimiento. Universidad de la República del Uruguay.

Braudel, F. (1974). La historia y las ciencias sociales. Alianza Editorial.

Brenner, R. (2013). La economía de la turbulencia global. Ediciones Era.

Demóstenes. (1980). Sobre la organización. Gredos.

Euclides. (2013). Elementos. Universidad de Santiago de Compostela.

Hegel, F. (2004). Filosofía del derecho. Juan Pablos Editores.

Hegel, F. (2013). Ciencia de la lógica. Editorial Las cuarenta. 
Lisi, F. (Ed.). (2015). Los filósofos presocráticos I. Gredos.

Luhmann. N. (2009). Introducción a la teoría de sistemas. UIA.

Morin, E. (1986). El método I. Editorial Cátedra.

Mumford, L. (2013). El mito de la máquina: técnica y evolución humana. Editorial Pepitas de Calabaza.

Mumford, L. (2016). El pentágono del poder: el mito de la máquina II. Editorial Pepitas de Calabaza.

Panitch, L., \& Gindin, S. (2015). La construcción del capitalismo global. Akal.

Platón. (2015a). La República. Diálogos IV. Gredos.

Platón. (2015b). Timeo. Diálogos IV. Gredos.

Plinio el Viejo. (1995). Historia natural. Libros I y II. Gredos.

Ponzio, A. (2011). La lógica de la publicidad y la ideo-lógica de la comunicación-producción global. DeSignis. Publicación de la Federación Latinoamericana de Semiótica, 17, 33-41.

The Economist. (2019). Inequality illusions [Editorial]. The Economist, p. 11.

Varrón. (1998). La lengua latina. Libros I y II. Gredos.

Vidal, R. (2007). Espacialidad, temporalidad y comunicación-red. Ediciones del Signo.

Wagensberg, J. (2001). Ideas sobre la complejidad del mundo. Tusquets. 